\title{
The Islamic Perspective of Lingual Dens Evaginatus in a Mandibular Left Second Premolar: A Case Report
}

\author{
Anisa Kusumawardani ${ }^{1}$, Yunita Dewi Ardini ${ }^{2}$, Taufiq Hidayat Hasan ${ }^{3}$ \\ ${ }^{1}$ Department of Conservative Dentistry, Kulliyyah of Dentistry, International Islamic University Malaysia, \\ Kuantan, Pahang, Malaysia \\ ${ }^{2}$ Department of Paediatric Dentistry, Kulliyyah of Dentistry, International Islamic University Malaysia, \\ Kuantan, Pahang, Malaysia \\ ${ }^{3}$ Department of Paediatrics, Kulliyyah of Medicine, International Islamic University Malaysia, Kuantan, \\ Pahang, Malaysia
}

\begin{abstract}
Dens evaginatus (DE) is a developmental anomaly. It is an extra cusp or tubercle that protrudes from the occlusal surface of posterior teeth, as well as the lingual surface of anterior teeth. Tubercles are susceptible to pulp exposure from wear or fracture because of malocclusion;leading to pulpal complications early after eruption.DE may also complicate the process of daily routine oral health care. A 13-year-old girl presented to our polyclinic with sinus track at the posterior lower left buccal gingiva forthe past1 year. All 35 teeth were sound. At the lingual side, there was an accessory tooth in close relation to tooth 35 covered with supra-gingival inflammation. Electric pulp test (EPT) showed that tooth 35 was already non-vital. Intraoral periapical (IOPA) radiograph and cone beam computed tomography (CBCT) scan showed an abnormalappearing root which shows DE with radiolucency at the periapical area. Root canal treatment was performed using crown down pressureless (CDP) technique and obturation was done using lateral condensation technique. The tooth was restored using composite restoration. DE is a rare condition. It is quite a challenge for dental practitioner since the diagnosis is difficult and the treatment options are limited. In the case of DE with necrotic pulp and periapical abscess, root canal treatment is a treatment of choice. We have to accept and appreciate any gift from Allah SWT whether it is good or bad, no equal divine creation except from Allah SWT.Therefore we need to take care of our oral hygiene to prevent diseases. In every disease, there is a cure; we thus need to try to do the best to find the cure and to not easily get rid of the tooth and replace it with a denture. Early diagnosis of DE can lead to proper treatment which can result in high success rate if it is followed by adequate restoration.
\end{abstract}

KEYWORDS: dens evaginatus, developmental anomaly, oral hygiene, root canal treatment

\section{INTRODUCTION}

Dens evaginatus (DE) is a developmental anomaly arising during morphodifferentiation that occurs more frequently in mandibular premolars $;^{1}$ although it can also affect other teeth including supranumerary teeth. ${ }^{2}$ It occurs in both primary and permanent dentitions. ${ }^{3,4}$ It is caused by abnormal proliferation of the inner enamel epithelium into the stellate reticulum of the enamel organ ${ }^{5}$ with a core of dentin surrounding a narrow extension of the pulp tissue projecting into the tubercle. ${ }^{6}$ Dens evaginatus is a condition affecting predominantly mandibular premolars and leading frequently to pulp necrosis because of occlusal trauma.

Periapical lesions on the radiographs may be

Corresponding author

Yunita Dewi Ardini

Department of Paediatric Dentistry,

Kulliyyah of Dentistry,

International Islamic University Malaysia,

Jalan Sultan Ahmad Shah,

25200 Kuantan,

Pahang, Malaysia

Email: dryunita@iium.edu.my misinterpreted as developing dental follicle. Diagnosis and treatment may be delayed and severe toothache or infection may occur because there is no obvious aetiology for a pulpitis such as caries or trauma. Immature root development in a young patient makes managing the affected teeth a problem.

The purpose of this case report is to present a management of lingual DE in mandibular left second premolar that interfered with the oral hygiene of the patient. A correlation of this case to the Islamic perspective is also analysed.

\section{Case Report}

A 13-year-old girl presented to IIUM dental polyclinic with gingival redness, sinus track and smelly odour at the posterior lower left buccal gingiva for the last 1 year. She had seeked treatment at several private clinics, but the doctors just gave her antibiotic and analgesic without any other treatment.

From the intraoral examination, 35 teeth were sound, although there was pain on percussion but 
no pain was elicited during palpation. On the lingual side there was an accessory tooth seen in close relation with the lingual distal side of tooth 35 covered with supra-gingival inflammation. Patient felt a slight discomfort at the surrounding area. Electric pulp test showed that tooth 35 was already non-vital.
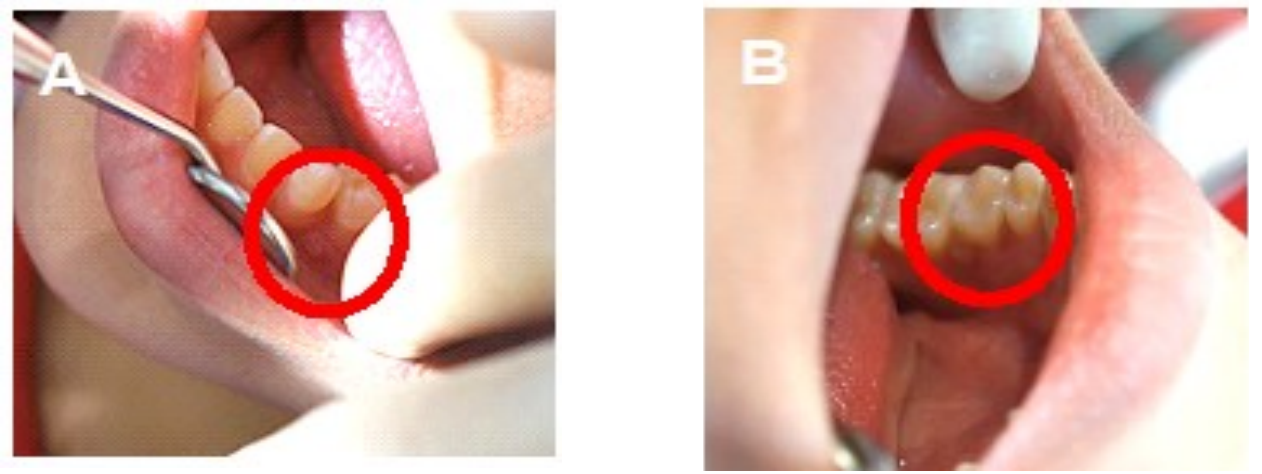

Figure 1. Sinus tract appeared at the buccal side between 34 and 35 since 1 year ago (A).An accessory tooth seen in close relation at the lingual distal side of tooth 35 covered with supra-gingival inflammation (B).

An intra-oral periapical radiograph and cone beam computed tomography scan was taken. Radiographic examination showed an abnormal-appearing tooth and root which correspond to DE with radiolucency at the periapical area. Access opening was performed from the occlusal of tooth 35 and pulp extirpation was done. Irrigation was done with Sodium hypochlorite $2.5 \%$ and normal saline. Dressing was performed by using non-setting Calcium hydroxide $\left(\mathrm{Ca}(\mathrm{OH})_{2}\right)$. The tooth was restored using Glass lonomer Cement as temporary restoration.

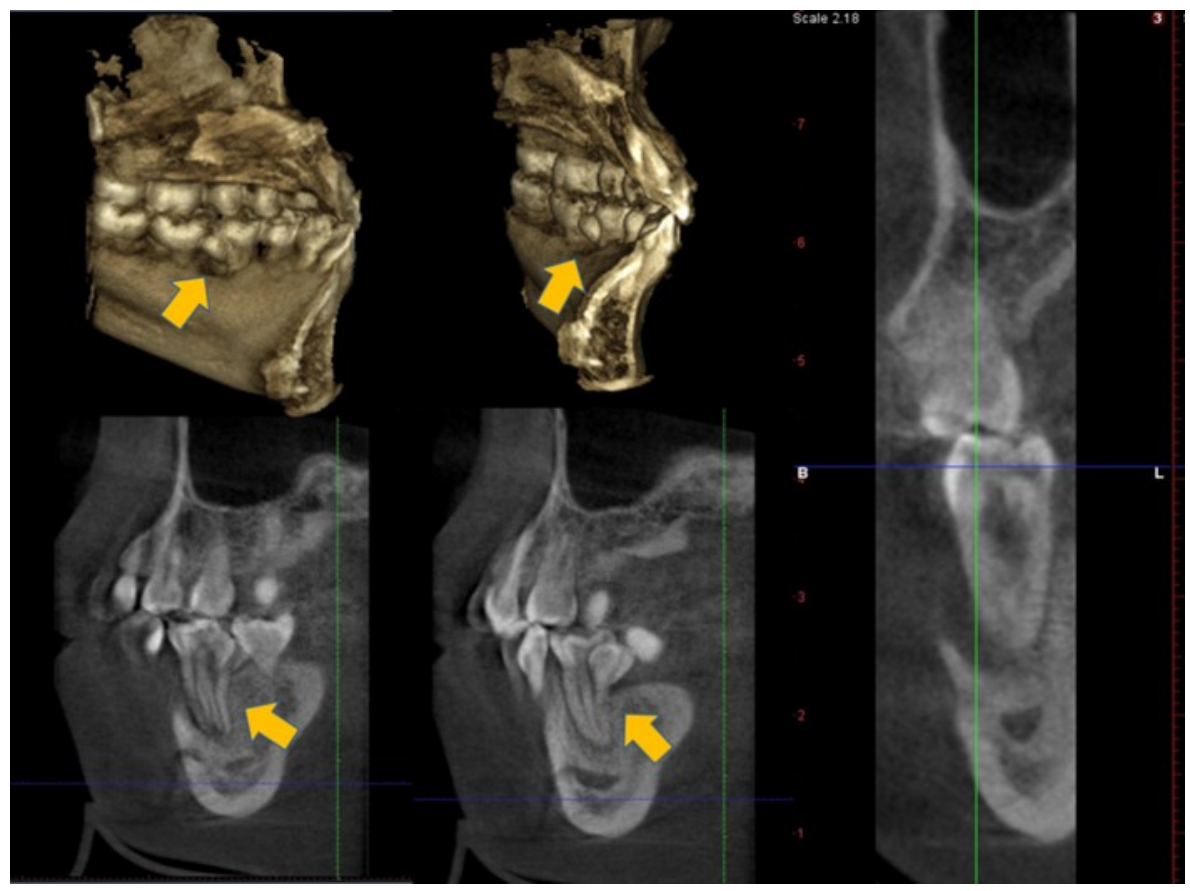

Figure 2: Cone Beam Computed Tomography scan of tooth 35.

On the second appointment of treatment, the sinus tract was found to have healed. The tooth and surrounding gingiva were not tender to percussion and palpation, and there were no more purulent discharge seen. Another dressing was performed.

Root canal treatment was performed on the third appointment. Cleaning and shaping was done by using crown down pressureless technique (Protaper instrument until size F4). Irrigation was done with Sodium hypochlorite $2.5 \%$ and normal saline.
Obturation was performed using lateral condensation technique with master gutta-percha (GP) cone F4 and accessory GP. AH26 was used as a root canal sealer. The tooth was restored using GIC restoration. There was no sign and symptom presented during review after 6 months obturation ( $4^{\text {th }}$ appointment). The tooth 35 was restored by using composite restoration. One year after obturation, the tooth was sound and can function normally. 

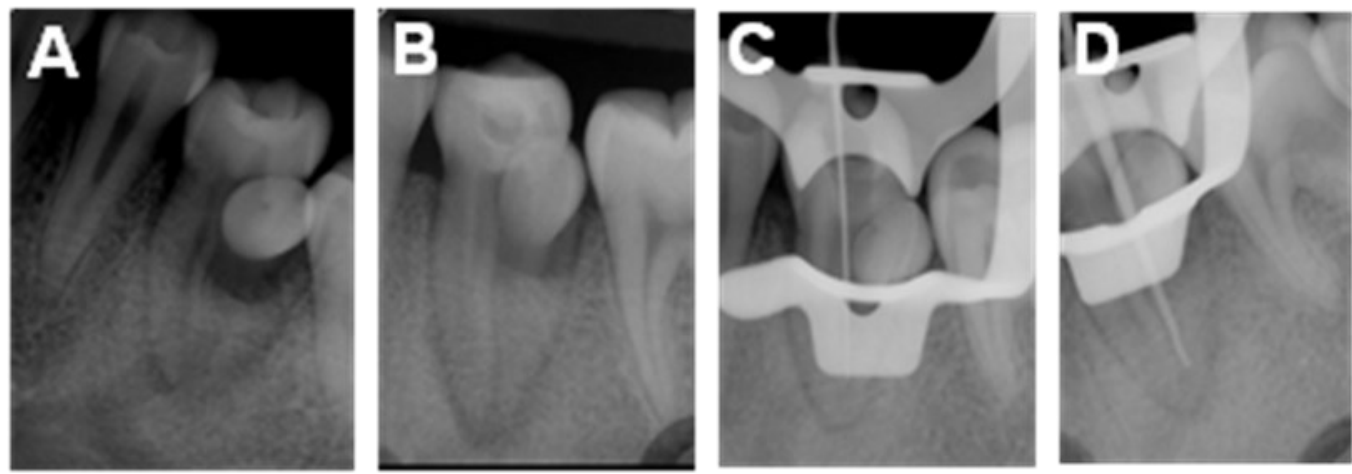

Figure 3: Pre-operative radiograph (A). Dressing with $\mathrm{Ca}(\mathrm{OH})_{2}$ after 3 months (B). Working length determination (C). Gutta-percha trial photo (D).
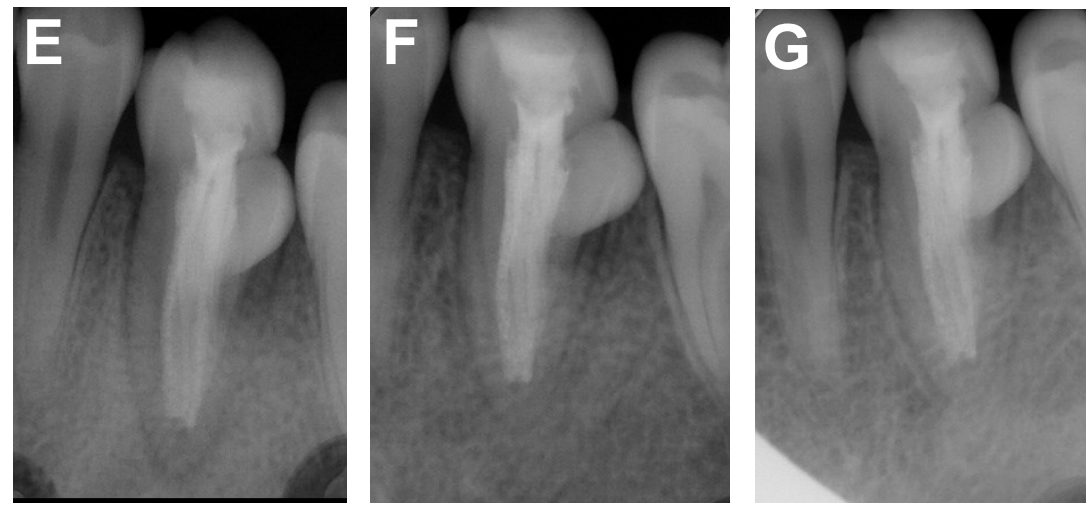

Figure 4: Obturation photo $(E)$. Control after 6 months obturation $(F)$. Control after 1 year obturation $(G)$.
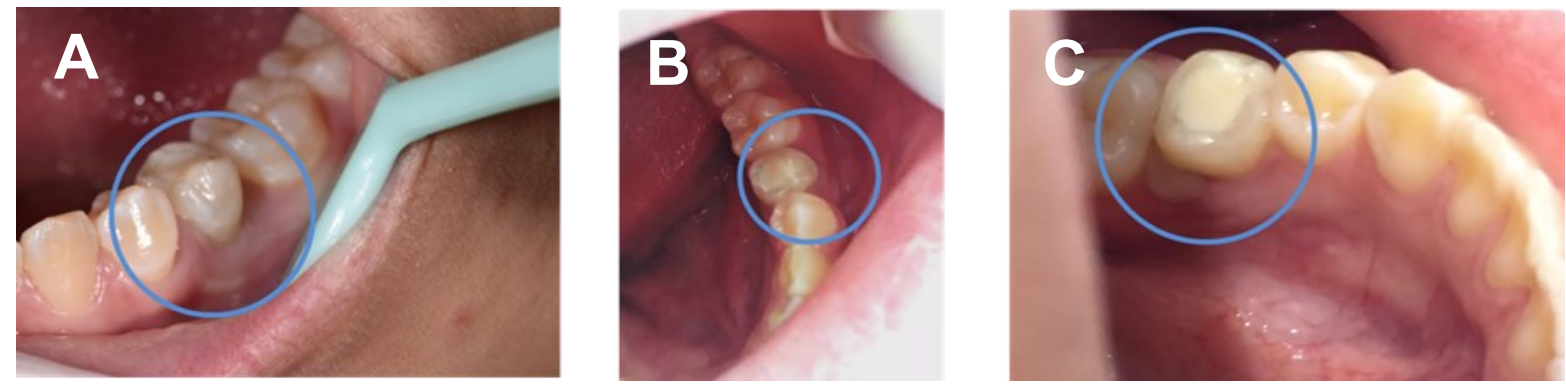

Figure 5. One year after treatment, no more swelling and purulent discharge (A and B).Placement of composite restoration $(C)$.

\section{DISCUSSIONS}

Dens evaginatus (DE) is a rare developmental anomaly in dentition. It is also quite a challenge for dental practitioner to treat, since the diagnosis is difficult and the treatment options are limited. Based on treatment determination of $\mathrm{DE}$, there are six categories of treatment which are shown in table $1 .^{7}$

Our case was included in type $V$ which was thetooth presenting with necrotic pulp and mature apex. The maturation of the root for second mandibular premolar is around 12-13 years. In this condition, conventional root canal therapy followed by proper restoration is the best treatment option.
Table 1: Six Categories to Determine Treatment of DE

\begin{tabular}{|c|c|}
\hline Type & Condition of the teeth \\
\hline$T$ & normal pulp and mature apex \\
\hline II & normal pulp and immature apex \\
\hline III & inflamed pulp and mature apex \\
\hline IV & inflamed pulp and immature apex \\
\hline V & necrotic pulp and mature apex \\
\hline VI & necrotic pulp and immature apex \\
\hline
\end{tabular}


As mentioned in the hadith: Abu Hurayrah narrates that The Prophet PBUH said: "There is no disease that Allah has created, except that He also has created its remedy". ${ }^{8}$ By doing root canal treatment we will remove all the infection inside the tooth and try to save the tooth from being extracted.

In every disease there is a cure; we need to try to do the best find the cure and to not easily get rid of the tooth and replace it with denture or artificial tooth. As mentioned

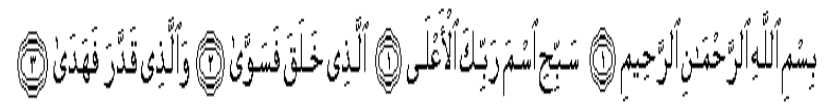

in the Surah Al-A'la verses 1-3: ${ }^{9}$

"Exalt the name of your Lord, the Most High (1). Who created and proportioned (2). And

who destined and [then] guided (3)."

Allah SWT creations are the best of creations. We have to accept and appreciate any gift from Allah SWT whether it is good or bad, no equal divine creation except from Allah SWT.

In the case of type I and type II, prophylaxis are necessary. The presence of DE may complicate the process of daily routine oral health care ${ }^{10}$ therefore incremental layering of an acid-etched flowable light-cured resin (AEFLCR) on the tubercle and surrounding surface are needed. ${ }^{7}$ When the tooth has opposing occluding surface, we need to reduce to eliminate traumatic occlusion with the tubercle, followed by applying topical fluoride to increase the enamel hydroxyapatite resistant to acid breakdown. Reevaluation is needed at 3 to 6 months intervals. Reevaluation is advised to check the occlusion and perform any necessary adjustments. Protection from many diseases can be achieved with cleanliness. We find that Islam commands individuals to pay attention to children's cleanliness and good nutrition. Due to the important function of the teeth, to prevent halitosis and to remove debris and plaque from the mouth, Islam adjures the rinsing of the mouth three times during each ablution, and encourages the use of a siwak (a device to brush the teeth). The same purpose can be accomplished through the use of toothbrush and toothpaste, which have not been known during the time of The Prophet Muhamad SAW, who said: "Lest I burden my community, I would have ordered them to use the siwak before each prayer". ${ }^{11,12}$ The Prophet, Peace Be Upon Him, also said: "The siwak cleans the mouth and pleases the Lord". ${ }^{13,14}$

\section{CONCLUSION}

Early diagnosis of DE with appropriate intra-oral and radiographic examination can lead to proper treatment which results in high success rate if it is followed by adequate restoration and good oral hygiene maintenance. We believe that each disease has a remedy but it is unto man to analyse and find the cure. Let us pray to Allah that He empowers our faith for the peace and tranquillity which are important factors for us to being an ideal society.

\section{REFERENCES}

1. Oehlers FA, Leek KW, Lee EC. Dens evaginatus (evaginatedodontome): its structure and responses to external stimuli. Dent Pract Dent $\operatorname{Rec} 1$ 1967; 17:239-44.

2. Al-Omari MAO, Hattab FN, Darwazeh AMG, Dummer PMH. Clinical problems associated with unusual cases of talon cusp. Int Endod J 1999; 32:183-90.

3. Hattab FN, Yassin OM. Bilateral talon cusps on primary central incisors: a case report. Int J Paediatr Dent 1996; 6:191-95.

4. Hattab FN, Yassin OM, Al-Nimri KS. Talon cusp clinical significance and management: case reports. Quintessence Int 1995; 26:115-20.

5. Tratman EK: An unrecorded form of the simplest type of the dilated composite odontome. Br Dent J 1949; 86:271-5.

6. Gallagher FJ, Cioffi GA, Taybos GM: Dens evaginatus: reportof a case. Quintessence Int 1988; 19:443-6.

7. Levitan ME, Himel VT. Dens Evaginatus: Literature Review, Pathophysiology, and Comprehensive Treatment Regimen. J Endod 2006; 32:1-9.

8. Sahih Bukhari. Available at: http:// www.fiqh.org/2009/04/every-illness-has-a-cure -the-islamic-perspective/. Accessed October 5, 2016.

9. [Holy Quran]. 87:1-3. [Arabic]

10. Nagarajan SMP, Sockalingam AM. Bilateral accessory central cusp of $2^{\text {nd }}$ deciduous molar: an unusual occurrence. Orofacial Sciences 2009; 4:22-4.

11. Sahih Muslim. [Al-Siwak] In: [Kitab Al-Taharah]. 1/220: Hadith 252. [Arabic].

12. Al-Tirmidhi. [Al-Siwak]. In: [Kitab Al-Thaharah]. 1/34: Hadith 22. [Arabic].

13. Sahih Bukhari. [Soft and hard siwak and its use while fasting]. In: [Kitab Al-Siyam]. 1/496. [Arabic].

14. Sunan Al-Nasa'i. [Encouraging the use of siwak]. In: [Kitab Al-Taharah]. 1/10. [Arabic]. 